\title{
Knowledge, Risk Perception and Practice Regarding Tuberculosis Transmission among Long Distance Bus Drivers in Addis Ababa, Ethiopia: A Cross Sectional Study
}

\author{
Tsegaye Tewelde Gebrehiwot $^{1 *}$, Fessahaye AlemsegedTesfamichael ${ }^{1}$
}

\section{OPEN ACCESS}

Citation: Tsegaye Tewelde Gebrehiwot, Fessahaye AlemsegedTesfamichael. Knowledge, Risk Perception and Practice Regarding Tuberculosis Transmission among Long Distance Bus Drivers in Addis Ababa, Ethiopia: A Cross Sectional Study. Ethiop J Health Sci.2017;27(6):601.

doi:http://dx.doi.org/10.4314/ejhs.v27i6.5

Received: May 23, 2017

Accepted: May 26, 2017

Published: November 1, 2017

Copyright: @ 2017 Tsegaye Tewelde, et al. This is an open access article distributed under the terms of the Creative Commons Attribution License, which permits unrestricted use, distribution, and reproduction in any medium, provided the original author and source are credited.

Funding: Jimma University funded the data collection section of this research project.

Competing Interests: The authors

declare that this manuscript was approved

by all authors in its form and that no

competing interest exists.

Affiliation and Correspondence:

Department of Epidemiology and

Biostatistics, College of public health and medical sciences, Jimma

University, Jimma, Ethiopia

*Email: tsegaye.tewelde@yahoo.com
BACKGROUND: Window opening during bus transportation is recommended as a tuberculosis prevention strategy.Yet, drivers are affected by lack knowledge and risk perception of passengers and assistants. Boosting knowledge of and notifying the high risk of tuberculosis transmission for every passenger could be too costly. However, strategies targeting bus drivers as key agents unlike targeting all passengers might be less costly for window opening.

METHOD: Data were collected from November 18/2014 to December 21/2014 in inter-region bus stations of Addis Ababa using cross sectional study design. Samples of 306 participants were selected using simple random sampling, and data were collected through face-to-face interview. Data were entered into Epi-data version 3.1 andanalyzed using IBM SPSS version 21.

RESULT: From a sample of 306 bus drivers, 303 were interviewed. Nine in ten and nearly half of participants believed in the for opening all windows and avoiding overcrowding of passengers as $T B$ preventive measures respectively. Few bus drivers (7.3\%) believed that bus drivers and their assistants could be at risk of tuberculosis. The majority (85.7\%) of bus drivers opened side window the whole day without precondition. Hearing tuberculosis related information from radio was a promoting factor for tuberculosis preventive measures among bus drivers. CONCLUSION: Tuberculosis preventive practices and knowledge of bus drivers seempositive (opportunities), despite their low risk perception (challenge). Using the opportunity, further empowering bus drivers to persuade passengers and assistants to open all the rest of the windows is needed. KEYWORDS: Tuberculosis, Knowledge, prevention practices, bus drivers, Ethiopia 


\section{INTRODUCTION}

In the globe, there has been major progress in reducing tuberculosis (TB) cases and deaths due to $\mathrm{TB}$ in the past two decades. TB declined at a rate of $2.2 \%$ between 2010 and 2011 (1) but at rate of $2 \%$ in 2012 (2). However, it remains the highest in Asia and Africa, especially in the South-East Asia regions and Sub-Saharan Africa (3-5). In 2013, of the total burdens of TB in the world, $56 \%$ and $25 \%$ were in South-East Asia and Western Pacific regions (6) and in Africa (7) respectively. In Ethiopia, tuberculosis is the major cause of death and hospital admission, and the country stands $7^{\text {th }}$ among the 22 highest burden countries (1-4, 7).

Mycobacterium tuberculosis infection might be experienced/caught at home, workplace or during travel and the risk of infection depends on exposure frequency to a source case and the duration of the exposure (6). However, the risk of tuberculosis infection among peoplein congregated settings (like jail, prison, shelter, workplaces, school, child care center, nursing home, social club, rehabilitation facility, residential areas or treatment facilities) is much higher than the risk in the general population setting (8). This can be because of "Indoors, tubercle bacilli are expelled into a finite volume of air unless there is ventilation and they may remain viable and suspended in the air for a prolonged period of time. Moreover, exposure time and density of infectious droplet nuclei are often, respectively, prolonged and high (6, 9) ". On the contrary, tubercle bacilli outdoors are rapidly dispersed and quickly become nonviable either by sunlight or even sky light, brief outside exposure and by chance $(6,10)$.

Bus transportation can be considered as congregated setting according to the definition given by World Health Organization (WHO), European Center for Disease Prevention and
Control and New Jersey Department of Health and Senior Services $(8,11-13)$. This indoor congregated setting could highly facilitate tuberculosis, multidrug resistant (MDR-TB) and extensively drug resistant (XDR-TB) transmission, if all windows of the bus are closed and passengers are overcrowded during travel (14). Window opening (adequate ventilation) in confined spaces or congregate settings was recommended to prevent tuberculosis and other infectious diseases transmitted by respiratory mode (15-21). Public ground transportations or bus transportation mode can be considered as one of the typical congregated settings. Window opening can serve as a potential tuberculosis preventive strategy in this case (14) .

Most of the Ethiopian population use mass road transportation modes to travel from one corner of the country to the other. Of these, bus transportation is the most common modality to travel long distances within the country (22-25). Similarly, $47.2 \%$ of the federal roads are paved (asphalt) (26), and most of the buses depart from inter-region bus stations of Addis Ababa, the capital city of Ethiopia, to different regions within the country use paved road. Most of the buses in Ethiopia are characterized by lack of automatic ventilation system. They rather have windows which can be manually manipulated by passengers and drivers. Every bus has one window for 2-3 seats for passengers and one side window for the driver. However, passengers do not usually open windows of the buses due to fear of cross breeze (air draft), which needs further investigation. As a result of this challenge, tuberculosis prevention strategies directly targeting at passengers might not be cost effective. Because of the nature of their work, bus drivers and their assistants spend most of their days travelling in such settings, which could facilitate exposure to indoor tubercle bacilli repeatedly and for a prolonged period of time. Hence, they are at higher risk of acquiring TB may be more than that of any passenger. Therefore, if bus drivers and their assistants are aware of the risk, there is a higher possibility that they can do their

DOI: http://dx.doi.org/10.4314/ejhs.v27i6.5 
best to convince/force their passengers to keep open all the windows. Such tuberculosis prevention behaviors are mainly influenced by knowledge, risk perception and attitude towards the disease as indicated in many previous community and facility based studies conducted in low and middle income countries among different segments of populations $(3,5,27-30)$.

However, current information about long distance bus drivers' knowledge, risk perception and practices towards tuberculosis transmission in such setting were limited in the Ethiopian context. Therefore, the aim of this study was to assess knowledge, risk perception and practice towards tuberculosis transmission among long distance bus drivers in Addis Ababa, Ethiopia. Similarly, this study was aimed at identifying predictors of overall TB preventive practices. The output of this study will help as evidence on the possible opportunities and challenges related to bus drivers' knowledge, risk perception and practice for stakeholders to design and implement TB prevention programmes on bus transportation using bus drivers as key agents.

\section{METHOD AND PARTICIPANTS}

Study setting: Data were collected from November 18/2014 to December 21/2014 in inter-region bus stations of Addis Ababa, the capital city of Ethiopia, with a population of 3,195,000 (31). There were three inter-region bus stations and fifteen public bus transport associations in Addis Ababa. Likewise, there were a total of 2,661 buses departing from/to these and all other stations located in different regions of Ethiopia. There were a total of 649 $1^{\text {st }}$ level, $3082^{\text {nd }}$ level and $493^{\text {rd }}$ level functional buses departing from/to the three inter-region bus stations of Addis Ababa during data collection period.
Study design and participants: A crosssectional design was employed in this study. A sample of eligible drivers of long distance inter-region buses departing from/to the three inter-regional bus stations of Addis Ababa were included in the survey. For a driver to be included to the survey, he/she had to have driven a bus for the last two weeks prior to the data collection.

Sampling procedure: The sample size was calculated using single population proportion formula, by considering estimated proportion of drivers who had practiced prevention practice for TB transmission during travel as 50\% (there was no information about drivers practice in the study area),95\% confidence level, 5\% margin of error (but since the total buses in the three bus stations were 1,006$)$, correction formula was employed. Thus, finally with the addition of $10 \%$ nonresponse a total of 306drivers were required. First, a list of 1,006 functional buses by their vehicle registration plate numbers which were collected from bus owners association was created. Their plate numbers (identification numbers) were entered into SPSS software and then computer generated simple random sampling technique was employed to select 306 buses randomly. Eventually, all the drivers (306) in the randomly selected buses were included in the survey.

Measurement: Bus drivers' tuberculosis prevention practices were assessed by asking questions about side window opening status, frequency and preconditions of side window opening, telling assistants and passengers to open all bus windows. The instrument also contains questions about the types of respiratory infections that can be transmitted during bus transportation, cause, mode of transmission, conditions that favor TB transmission during travel, signs and symptoms, specific preventive measures during travel in bus, general preventive measures, peoples at risk of TB and bus drivers' over all knowledge about TB. Other variables included in the study were socio-demographic and economic characteristics of bus drivers. Overall TB prevention practice was the dependent variable categorized as good and bad. Drivers who keep open the side window of the bus without precondition and told assistants and passengers

DOI: http://dx.doi.org/10.4314/ejhs.v27i6.5 
every day to keep open the rest windows of the bus were considered as having good overall TB prevention practice, otherwise bad practice. Driver who keep open the side window of the bus without precondition was coded as ' 1 ' otherwise coded as ' 0 '. Driver who told assistants every day to keep open the rest windows of bus was coded as ' 1 ' otherwise ' 0 ' and driver who told passengers daily to keep open the rest windows of bus was coded as ' 1 ' otherwise ' 0 '. These three variables were computed to get an overall TB prevention practice. Drivers who got a score of three for this variables were considered as having good overall TB prevention practice; otherwise, they were considered as having bad practice. The regression analysis to identify predictors for overall TB prevention practice was done based on this categorization. 'Bus driver assistant' was defined as a cashier or technician working in the bus with the driver. Side window is a window located on the left side of the driver, which is designed to have air ventilation, hear motor sound, hear traffic police and for other purposes. Similarly, personal yearly income of bus drivers was classified as: low income $(\leq 388 \$)$, lower middle income (388$1,808 \$$ ], upper middle income $(1,808-5,175 \$$ ] and high income $(>5,175 \$)(32)$.

The interview questionnaire was prepared in English and translated into Amharic language, the working language of Ethiopia, and thereafter back translation was done by another person to check for consistency. Data were collected through faceto-face interview using interviewer-administered structured questionnaire at a convenient place and time (before their trips) for bus drivers. A total of seven data collectors were recruited from governmental employees working in the transport facilitation and coordinating offices in the three inter-regional bus stations of Addis Ababa. Three $\mathrm{BSc}$ nurses were recruited as supervisors, and one supervisor was assigned to each bus station. A one day training was given for both data collectors and supervisors. Next, the questionnaire was pre-tested on $5 \%$ of the sample before the actual data collection days on bus drivers departing from/to other $4^{\text {th }}$ smaller non-inter-regional bus station located in Addis Ababa and then necessary correction was made.

Data processing and analysis: Data were edited manually before entry to a computer, entered into Epi-data version 3.1 and analyzed using IBM SPSS version 21 for windows. Descriptive analysis was done to get summary values of tuberculosis prevention practices, knowledge about tuberculosis and socio-demographic and economic status variables and to check for outliers, inconsistencies and missed values. Binary and multivariable logistic regression analysis was undertaken to identify predictors of overall tuberculosis prevention practice. Sociodemographic and knowledge about tuberculosis related factors of bus drivers were considered for adjustment using logistic regression. All variables of these categories that fulfilled chi-square assumptions were entered to multivariable logistic regression for adjustment as indicated in Table 5. Then, variables were considered significant if the $\mathrm{p}$-value was less than 0.05 . Finally, the results were presented in the form of tables and texts.

Ethical consideration: Ethical clearance was obtained from the Health Sciences College Institutional Review Board of Jimma University. Trained interviewers informed the participants that participation in the study was voluntary. Participants were also assured about confidentiality of the information to be provided and were informed not to answer any question during the interview if they feel unconfortable . Data were used only for the purpose of the study. Oral consent was obtained from the study participants before the actual data collection. The consent form was developed by the research team and approved by the Ethical Committee of Jimma University.

\section{RESULT}

Socio-demographic and Economic characteristics: From a total sample of 306 bus drivers, 303 were participated in the study, which makes a response rate of $99.02 \%$. Nearly $58 \%$ and $33 \%$ of the drivers were in the age category of 30 44 and above 44 years respectively. With respect

DOI: http://dx.doi.org/10.4314/ejhs.v27i6.5 
to educational and marital status, $86.8 \%$ and $79.9 \%$ of the bus drivers were from grade 1 to 12 and married respectively. Similarly, $80.5 \%$ of them had children, and $55.4 \%$ fellin the upper middle income category (Table 1).

Table 1: Socio-demographic and economic characteristics of long distance bus drivers in bus stations of Addis Ababa, Ethiopia, 2014.

\begin{tabular}{|c|c|c|}
\hline Variable & Categories & Frequency $(\%)$ \\
\hline \multirow[t]{2}{*}{ Residence } & Urban & $295(97.4)$ \\
\hline & Rural & $8(2.6)$ \\
\hline \multirow[t]{3}{*}{ Age in years } & $18-29$ & $15(5.0)$ \\
\hline & $30-44$ & $186(61.3)$ \\
\hline & $\geq 45$ & $102(33.7)$ \\
\hline \multirow{4}{*}{$\begin{array}{l}\text { Educational } \\
\text { status }\end{array}$} & Illiterate & $4(1.3)$ \\
\hline & Grade 1-12 & $263(86.8)$ \\
\hline & Above & $36(11.9)$ \\
\hline & Secondary & \\
\hline \multirow[t]{5}{*}{ Religion } & Orthodox & $245(80.8)$ \\
\hline & Muslim & $25(8.3)$ \\
\hline & Protestant & $17(5.6)$ \\
\hline & Catholic & $14(4.6)$ \\
\hline & Others & $2(0.7)$ \\
\hline \multirow[t]{5}{*}{ Ethnicity } & Amhara & $129(42.6)$ \\
\hline & Oromo & $84(27.7)$ \\
\hline & Guraghe & $42(13.8)$ \\
\hline & Tigrie & $35(11.6)$ \\
\hline & Other & $12(4.0)$ \\
\hline \multirow[t]{3}{*}{ Marital status } & Married & $242(79.9)$ \\
\hline & Single & $52(17.2)$ \\
\hline & Widowed & $9(2.9)$ \\
\hline \multirow[t]{2}{*}{ Having Child } & Yes & $244(80.5)$ \\
\hline & No & $59(19.5)$ \\
\hline \multirow{5}{*}{$\begin{array}{l}\text { Personal yearly } \\
\text { income in } \\
\text { USD }\end{array}$} & Lower middle & $133(44.0)$ \\
\hline & Income (388- & \\
\hline & Upper middle & $168(55.4)$ \\
\hline & $\begin{array}{l}\text { Income }(1,808- \\
5,175)\end{array}$ & \\
\hline & $\begin{array}{l}\text { High income } \\
(>5,175)\end{array}$ & $2(.6)$ \\
\hline
\end{tabular}

Knowledge about tuberculosis: Almost all (98.3\%) of the bus drivers had ever heard of respiratory infections transmitted during travel in buses, and all of these mentioned the possibility of transmission of tuberculosis during travel in buses. Besides, nearly all (99.7\%) of them had ever heard of the disease 'tuberculosis', out of which nearly half $(48.3 \%)$ heard the information on the radio. On the other hand, germs were mentioned as the perceived causes of tuberculosis by nine in ten bus drivers, but the rest $(10.3 \%)$ of the drivers had misconceptions about the cause of TB. Similarly, $93.3 \%$ and $56.3 \%$ of the bus drivers believed that cough for two weeks or more and Hemoptysis are the symptoms of TB respectively (Table 2).

Knowledge about tuberculosis prevention measures:Poor ventilation, presence of active TB case and overcrowding of passengers were mentioned as conditions which favor tuberculosis transmission during travel in buses, by $72.8 \%$, $53 \%$ and $47 \%$ bus drivers respectively. Likewise, nine in ten and half of the bus drivers considered opening all windows of bus and avoiding overcrowding of passengers as TB preventive measures during travel in buses respectively (Table 3).

Tuberculosis was considered as a preventable disease by almost all (98.3\%) of the bus drivers. On top of this, avoiding overcrowding, safe disposal of sputum, adequate ventilation of living rooms and avoiding coughing in front of people were cited as general TB preventive measures by nearly $1 / 3^{\text {rd }}$ to $9 / 10^{\text {th }}$ of the bus drivers. On the other hand, a non-negligible portion of the bus drivers had misconception on the general prevention measures of tuberculosis: avoid sharing of dishes $(25.8 \%)$, avoiding sex with TB patients $(21.5 \%)$ and avoid shaking hands $(11.9 \%)$ were wrongly considered as TB prevention measures by participants. Although $83.1 \%$ of the bus drivers recognized that any person could be at risk of tuberculosis disease, only $7.3 \%$ of them believed that bus drivers and their assistants could be at risk of the disease. Furthermore, nearly all (97.7\%) of the bus drivers responded that tuberculosis is a curable disease (Table 3 ).

Tuberculosis prevention practice:Almost all of the bus drivers (99.3\%) had ever opened the side windows of buses in the last two weeks prior to data collection. Two hundred fifty eight $(85.7 \%)$ of them always opened the side windows of buses without any precondition whereas almost all the rest $(12.9 \%)$ opened the side window of the bus when the air condition becomes hot. Nearly eight

DOI: http://dx.doi.org/10.4314/ejhs.v27i6.5 
in ten $(81.7 \%)$ and almost seven in ten $(67.1 \%)$ of the bus drivers opened side windows of buses to prevent respiratory diseases and heat respectively (Table 4).

Table 2: Knowledge about tuberculosis diseases among long distance bus drivers in bus stations of Addis Ababa, Ethiopia, 2014.

\begin{tabular}{|c|c|c|c|}
\hline Variables & Categories & Frequency & $\begin{array}{l}\text { Percentage } \\
(95 \% \text { CI })\end{array}$ \\
\hline \multicolumn{4}{|c|}{ Heard of respiratory Infections transmitted during bus travel $(n=303)$} \\
\hline & Yes & 298 & 98.3(96.7, 99.7) \\
\hline & No & 5 & $1.7(0.3,3.3)$ \\
\hline \multicolumn{4}{|c|}{ Respiratory infections transmitted during bus travel $(n=298)$} \\
\hline & Tuberculosis & 298 & 100 \\
\hline & Common cold & 171 & $57.4(51.5,63.1)$ \\
\hline & Influenza & 96 & $32.2(27.0,37.4)$ \\
\hline & Measles & 39 & $13.1(9.4,17.4)$ \\
\hline \multicolumn{4}{|c|}{ Heard of tuberculosis infection $(n=303)$} \\
\hline & Yes & 302 & $99.7(99.0,100)$ \\
\hline & No & 1 & $0.3(0.0,1.0)$ \\
\hline \multicolumn{4}{|c|}{ Source of information for tuberculosis $(n=302)$} \\
\hline & Radio & 146 & $48.3(42.4,53.8)$ \\
\hline & Health professionals & 97 & $32.1(26.7,37.7)$ \\
\hline & Television & 83 & $27.5(22.2,32.8)$ \\
\hline & Magazine and news paper & 53 & $17.5(13.2,22.2)$ \\
\hline \multicolumn{4}{|c|}{ Perceived cause of TB $(n=302)$} \\
\hline & Germs & 271 & $89.7(86.1,92.9)$ \\
\hline & Cold air & 10 & $3.3(1.5,5.4)$ \\
\hline & Other & 21 & $7.0(4.3,9.9)$ \\
\hline \multicolumn{4}{|c|}{ Perceived symptoms of TB $(n=302)$} \\
\hline & Cough for 2 weeks or more & 281 & 93.3(90.1, 95.8) \\
\hline & Hemoptysis & 170 & $56.3(50.7,61.4)$ \\
\hline & Fever for 2 weeks or more & 89 & $29.5(23.8,35.8)$ \\
\hline & Weight loss & 86 & $28.5(23.2,33.2)$ \\
\hline \multicolumn{4}{|c|}{ TB can transmit during travel in bus $(n=302)$} \\
\hline & Yes & 298 & 98.7(97.4, 99.7) \\
\hline & No & 4 & $1.3(0.3,2.6)$ \\
\hline
\end{tabular}

On the top of these, near to eight in ten of the bus drivers ever told their assistants and passengers to open bus windows in the last two weeks prior to data collection, of which nearly seven in ten (70.4\%) and half $(54.1 \%)$ told their assistants and passengers everyday to open bus windows respectively. When asked about the purpose, $83.2 \%$ and $64.6 \%$ of the drivers told assistants and/ or passengers to open bus windows for the prevention of respiratory diseases and heat respectively. In addition, almost nine in ten $(87.8 \%)$ of the bus drivers indicated their assistants had ever opened windows of buses in the last two weeks prior to data collection. Similarly, nearly eight in ten $(81.5 \%)$ of the bus drivers responded as their assistants had ever told passengers to open bus windows (Table 4). 
Table 3: Knowledge about tuberculosis prevention measures among long distance bus drivers in bus stations of Addis Ababa, Ethiopia, 2014.

\begin{tabular}{|c|c|c|c|}
\hline Variables & Categories & Frequency & $\begin{array}{l}\text { Percentage } \\
(95 \% \mathrm{CI})\end{array}$ \\
\hline \multicolumn{4}{|c|}{ Conditions which favors TB transmission during bus travel $(n=302)$} \\
\hline & Poor ventilation when windows closed & 220 & $72.8(68.4,77.6)$ \\
\hline & Presence of active TB case & 160 & $53(47.0,59.4)$ \\
\hline & Overcrowding of passengers & 142 & $47(41.7,52.8)$ \\
\hline & High temperature & 47 & $15.6(12.1,19.7)$ \\
\hline \multicolumn{4}{|c|}{ TB is preventable diseases $(n=302)$} \\
\hline & Yes & 297 & $98.3(96.7,99.7)$ \\
\hline & No & 2 & $0.7(0.0,1.7)$ \\
\hline & Not sure & 3 & $1.0(0.0,2.3)$ \\
\hline \multicolumn{4}{|c|}{ TB preventive measures during travel in bus $(n=302)$} \\
\hline & Opening all windows of bus & 273 & $90.4(86.9,93.4)$ \\
\hline & Avoiding overcrowding of passengers & 144 & $47.7(42.4,53.4)$ \\
\hline & Decreasing temperature during travel in bus & 42 & $13.9(10.3,18.2)$ \\
\hline \multicolumn{4}{|c|}{ General preventive measures of TB $(n=302)$} \\
\hline & Avoiding coughing in front of people & 264 & $87.4(83.3,91.4)$ \\
\hline & Avoiding overcrowding & 110 & $36.4(30.1,41.4)$ \\
\hline & Adequate ventilation of living rooms & 169 & $56(49.9,62.1)$ \\
\hline & Safe disposal of sputum & 163 & $54(48.9,59.6)$ \\
\hline & Avoid sharing of dishes & 78 & $25.8(20.4,30.8)$ \\
\hline & Avoiding sex with TB patients & 65 & $21.5(16.8,26.5)$ \\
\hline & Avoid shaking hands & 36 & $11.9(8.1,15.9)$ \\
\hline \multicolumn{4}{|c|}{ Peoples at risk of TB infection and/disease $(n=302)$} \\
\hline & Any person & 251 & $83.1(78.5,87.1)$ \\
\hline & People living with HIV & 47 & $15.6(11.9,20.0)$ \\
\hline & Drug users & 26 & $8.6(6.0,12.4)$ \\
\hline & Drivers and their assistants & 23 & $7.6(4.8,11.1)$ \\
\hline & Prisoners & 23 & $7.6(4.6,10.1)$ \\
\hline \multicolumn{4}{|c|}{ Can TB be cured $(n=302)$} \\
\hline & Yes & 295 & $97.7(95.9,99.3)$ \\
\hline & No & 7 & $2.3(0.7,4.1)$ \\
\hline
\end{tabular}

Predictors of overall tuberculosis prevention practice: Bus drivers who heard tuberculosis related information from radio had good TB prevention practice nearly two times as compared to those who didn't heard information from radio (Table 5).

DOI: http://dx.doi.org/10.4314/ejhs.v27i6.5 
Table 4: Tuberculosis prevention practices of long distance bus drivers and their assistants in bus stations of Addis Ababa, Ethiopia, 2014.

\begin{tabular}{|c|c|c|c|}
\hline Variable & Categories & Frequency & Percentage $(95 \% \mathrm{CI})$ \\
\hline \multicolumn{4}{|c|}{ Side window opening in last 2 weeks $(n=303)$} \\
\hline & Yes & 301 & $99.3(98.3,100)$ \\
\hline & No & 2 & $0.7(0,1.7)$ \\
\hline \multicolumn{4}{|c|}{ Preconditions for side window opening in last two weeks $(n=301)$} \\
\hline & Always (with no precondition) & 258 & $85.7(81.7,90.2)$ \\
\hline & When it is hot & 39 & $12.9(9,16.6)$ \\
\hline & Others & 4 & $1.4(0.3,2.7)$ \\
\hline \multicolumn{4}{|c|}{ Purpose of opening side window $(n=301)$} \\
\hline & To prevent respiratory disease & 246 & $81.7(77.1,85.7)$ \\
\hline & To prevent heat & 202 & $67.1(61.5,72.4)$ \\
\hline & To answer the request of other's & 43 & $14.3(11,18.3)$ \\
\hline & To hear motor sound & 22 & $7.3(4.7,10.3)$ \\
\hline \multicolumn{4}{|c|}{ Number of days told assistants to open window of bus $(n=303)$} \\
\hline & Everyday & 176 & $70.4(52.1,63.4)$ \\
\hline & Most of the days & 55 & $22(13.9,22.9)$ \\
\hline & Some of the days & 10 & $4(1.3,5.3)$ \\
\hline & None & 53 & $17.5(13.2,22.4)$ \\
\hline & Others & 9 & $3.6(1.0,5.0)$ \\
\hline \multicolumn{4}{|c|}{ Number of days told passengers to open window of bus $(n=303)$} \\
\hline & Every day & 164 & $54.1(48.1,59.7)$ \\
\hline & Most of the days & 64 & $21.1(16.2,26.1)$ \\
\hline & Some of the day & 7 & $2.3(0.7,4.1)$ \\
\hline & None & 60 & $19.8(15.7,23.9)$ \\
\hline & Others & 8 & $2.6(1.0,4.7)$ \\
\hline \multicolumn{4}{|c|}{ Purpose of telling assistants and/passengers to open windows $(n=268)$} \\
\hline & To prevent respiratory disease & 223 & $83.2(78.6,87.3)$ \\
\hline & To prevent heat & 173 & $64.6(59.7,69.7)$ \\
\hline & To answer the request of other's & 33 & $12.3(8.5,16.0)$ \\
\hline \multicolumn{4}{|c|}{ Assistants ever opened window of bus $(n=303)$} \\
\hline & Yes & 266 & $87.8(84.2,91.1)$ \\
\hline & No & 37 & $12.2(8.9,15.8)$ \\
\hline \multicolumn{4}{|c|}{ Assistants ever tell passengers to opened window of bus $(n=303)$} \\
\hline & Yes & 247 & $81.5(76.2,85.9)$ \\
\hline & No & 56 & $18.5(14.1,23.8)$ \\
\hline
\end{tabular}

\section{DISCUSSION}

Our study shows that the majority $(85.7 \%)$ of the bus drivers opened the side windows of buses without any precondition, indicating a good practice. Similarly, more than half of the bus drivers told everyday their assistants and passengers to open the windows of buses. Opening all windows and avoiding overcrowding of passengers were considered by participants as TB preventive measures. Few bus drivers indicated that bus drivers and their assistants could be at risk of the disease. Hearing tuberculosis related information from radio was a promoting factor for tuberculosis preventive measures. These imply 
Table 5: Predictors of tuberculosis over all prevention practice among long distance bus drivers in bus stations of Addis Ababa, Ethiopia, 2014.

\begin{tabular}{|c|c|c|c|c|c|c|}
\hline \multicolumn{7}{|c|}{ Over all TB prevention practice } \\
\hline Variables & Categories & Yes $(\%)$ & No $(\%)$ & COR $(95 \% \mathrm{CI})$ & P-value & AOR $(95 \% \mathrm{CI})$ \\
\hline \multirow[t]{3}{*}{ Age } & $18-29$ & $4(3.0 \%)$ & $11(6.5 \%)$ & 1 & 0.168 & \\
\hline & $30-44$ & $89(66.4)$ & $96(57.1)$ & $2.55(.78,8.30)$ & 0.120 & \\
\hline & $\geq 45$ & $41(30.6)$ & $61(36.3)$ & $1.85(.55,6.20)$ & 0.320 & \\
\hline \multirow{2}{*}{ Children } & Yes & $107(80)$ & $136(80.8)$ & 1 & 0.810 & \\
\hline & No & $27(20)$ & $32(19.2)$ & $1.07(0.60,1.90)$ & & \\
\hline \multicolumn{7}{|l|}{ Source of information for TB } \\
\hline \multirow[t]{2}{*}{ Radio } & Yes & $77(57.5)$ & $69(41.1)$ & $1.94(1.22,3.07)$ & & $1.9(1.1,3.2) *$ \\
\hline & No & $57(42.5)$ & $99(58.9)$ & 1 & 0.005 & 1 \\
\hline \multirow[t]{2}{*}{ Health professionals } & Yes & $46(34.3)$ & $51(30.4)$ & $1.20(.74,1.95)$ & & $1.7(0.96,3.06)$ \\
\hline & No & $88(65.7)$ & $117(69.6)$ & 1 & 0.463 & 1 \\
\hline \multirow[t]{2}{*}{ Television } & Yes & $32(23.9)$ & $51(30.4)$ & 1 & 0.211 & \\
\hline & No & 102(76.1) & 117(69.6) & $1.39(.83,2.33)$ & & \\
\hline \multirow{2}{*}{$\begin{array}{l}\text { Germs as perceived cause of } \\
\text { TB }\end{array}$} & Yes & 126(94.0) & $145(86.0)$ & $2.50(1.08,5.78)$ & & $2.2(0.92,5.35)$ \\
\hline & No & $8(6.0)$ & 23(13.7) & 1 & .032 & 1 \\
\hline \multicolumn{7}{|c|}{ favorable conditions for TB transmission during travel in bus } \\
\hline \multirow{2}{*}{$\begin{array}{l}\text { Poor ventilation when } \\
\text { windows closed }\end{array}$} & Yes & $81(60.4)$ & 139(82.7) & $0.32(0.19,0.54)$ & & \\
\hline & No & $53(39.6)$ & $29(17.3)$ & 1 & 0.001 & \\
\hline \multirow[t]{2}{*}{ Presence of active TB case } & Yes & $82(61.2)$ & $78(46.4)$ & $1.82(1.15,2.89)$ & & $1.6(0.98,2.75)$ \\
\hline & No & $52(38.8)$ & $90(53.6)$ & 1 & 0.001 & 1 \\
\hline \multirow[t]{2}{*}{ Overcrowding of passengers } & Yes & $54(40.3)$ & $88(52.4)$ & $0.61(0.39,0.97)$ & & \\
\hline & No & $80(59.7)$ & $80(47.6)$ & 1 & 0.037 & \\
\hline \multicolumn{7}{|c|}{ TB preventive measures during travel in bus } \\
\hline \multirow[t]{2}{*}{ Opening all windows of bus } & Yes & 123(91.8) & $150(89.3)$ & $1.34(0.61,0.95)$ & & \\
\hline & No & $11(8.2)$ & 18(10.7) & 1 & 0.464 & \\
\hline \multirow{2}{*}{$\begin{array}{l}\text { Avoiding overcrowding of } \\
\text { passengers }\end{array}$} & Yes & $58(43.3)$ & $86(51.2)$ & $0.73(0.46,1.15)$ & & \\
\hline & No & $76(56.7)$ & $82(48.8)$ & 1 & 0.172 & \\
\hline \multicolumn{7}{|c|}{ Peoples at risk of TB infection and/disease } \\
\hline \multirow[t]{2}{*}{ Any person } & Yes & 119(88.8) & 132(78.6) & $2.16(1.13,4.15)$ & & \\
\hline & No & 15(11.2) & $36(21.4)$ & 1 & 0.020 & \\
\hline \multirow[t]{2}{*}{ People living with HIV } & Yes & 19(14.2) & $28(16.7)$ & $0.83(0.44,1.56)$ & & \\
\hline & No & $115(85.8)$ & $140(83.3)$ & 1 & 0.554 & \\
\hline \multirow[t]{2}{*}{ Drivers and their assistants } & Yes & $6(4.5)$ & $16(9.5)$ & $0.42(0.16,1.09)$ & & \\
\hline & No & 128(95.5) & 152(90.5) & 1 & 0.074 & \\
\hline \multirow[t]{2}{*}{ Prisoners } & Yes & $6(4.5)$ & $17(10.1)$ & $0.45(0.17,1.17)$ & & \\
\hline & No & $128(95.5)$ & $151(89.9)$ & 1 & 0.101 & \\
\hline
\end{tabular}

*indicates significant variable at 0.05 level of significance

the presence of a fertile ground for further interventions using bus drivers as key agents to persuade passengers and drivers to open all windows of buses despite their low risk perception.

This study highlighted that more than half of the bus drivers told their assistants and passengers everyday to open the bus windows. This indicates efforts are made by bus drivers to open the rest of the windows. Hence, intervention strategies to open the rest of the bus windows using bus drivers as key responsible persons could be efficient and effective in preventing tuberculosis transmission during travel. Besides, nearly $83 \%$ of the bus drivers told their assistants and/or passengers to open windows for the prevention of respiratory

DOI: http://dx.doi.org/10.4314/ejhs.v27i6.5 
diseases. This implies a small effort might be needed to inform bus drivers about the purpose of opening bus windows.

Almost all $(98.3 \%)$ of the bus drivers had ever heard of respiratory infections transmitted during travel in buses, and a similar proportion of them mentioned the possibility of transmission of tuberculosis during travel in buses. This might show that tuberculosis prevention programmes through different Media were also reaching this segment of the population. Besides, nearly half heard about tuberculosis disease from radio, and this was consistent with the finding from a study done in Uganda (50\%) (33). However, this was higher than studies done in Tigray (3.2\%) (34) and in Gambella (0.95\%) (35). This might be due to difference in population characteristics. The bus drivers in this study were almost all literate (98.7\%) which could facilitate understanding. Similarly, because of the nature of their occupation, bus drivers could have access to public radio that facilitate listening and gaining information. However, the participants in the previous studies were part of the general population, have low access to radio and less educated.

In addition, germs were mentioned as perceived causes of tuberculosis by almost all bus drivers. However, this was higher than figures from previous studies in Southwest Ethiopia (33.7\%) (3), in Tigray (9.6\%) (34), in Afar $(0.25 \%)(4)$, in Gambella $(3.3 \%)(35)$, and in Uganda $(26.7 \%)(33)$. This could be the result of difference in literacy status, which could influence understanding of TB related information. Bus drivers in this study were almost all literate unlike those in the previous studies, mentioned earlier. Moreover, most of the drivers lived in Addis Ababa, the capital city of Ethiopia, in which drivers could have access to information through different Media unlike the population in the previous studies. Poor ventilation, presence of active pulmonary TB case and overcrowding of passengers were mentioned as conditions which favor tuberculosis transmission during travel in buses by most of the bus drivers. Likewise, our study indicated that bus drivers considered opening all windows of buses and avoiding overcrowding of passengers as TB preventive measures during travel in buses. This highlights the effectiveness of current tuberculosis prevention programmes in reaching this portion of the population to raise awareness about tuberculosis in this country. This could thus lay a fertile ground for further TB prevention programmes mediated by bus drivers.

On the other hand, our findings highlighted that the majority $(83.1 \%)$ of the bus drivers mentioned that any person could be at risk of tuberculosis disease. However, this was inconsistent with studies done in Uganda $(68.7 \%)$ (33) and in Tajikistan (69\%) (36). Due to the nature their occupation, bus drivers might have access to public radio to gaining information about tuberculosis but this might not be true in the previous studies. However, only few (7.3\%) believed that bus drivers and their assistants could be at risk of TB disease. Because of the nature of their working, bus drivers and their assistants spend most of their days travelling in this congregated setting (bus transportation). As a result, they might be exposed to indoor tubercle bacilli repeatedly and for a prolonged period of time even though their perceived risk of tuberculosis is low. If this remains unresolved, bus transportation might continue to be a potential source of tuberculosis, which in turn challenges the disease prevention and control efforts made in this country. In addition, this low risk perception might be a challenge for stakeholders who could use bus drivers as key agents for the prevention of tuberculosis transmission during bus travel. Additionally, the low risk perception might indicate that current tuberculosis prevention programmes lack disseminating comprehensive information about the disease.

On the other hand, hearing tuberculosis related information on the radio was a promoting factor for overall TB prevention practices. This implies that TB prevention programmes influencing prevention practices during travel in buses could be effective if disseminated through radio.

This study can have its own limitation. The assessment of two weeks' tuberculosis prevention practices might over or under estimate bus drivers' usual practice.

On the other hand, the reported tuberculosis prevention practices were based on self-report of bus

DOI: http://dx.doi.org/10.4314/ejhs.v27i6.5 
drivers. This could overestimate the actual practice. Lastly, the practice of opening windows of buses could vary between rainy and non-rainy seasons, but the practices here in this study depict only the fact for the non-rainy season. To minimize possible reporting bias by participants, data collectors persuaded interviewees to report their actual practices by putting emphasis on the objective and policy implication of the study while taking consent.

In conclusion, tuberculosis preventive practices and knowledge of bus drivers seem good (opportunities), despite their low risk perception (challenge). Using the opportunities, a new tuberculosis preventive strategy should be designed to further empower bus drivers thereby persuading passengers and assistants. Because opening all windows of bus persistently the whole day depends on the persuasion of passengers and assistants. Besides, large scale research should be conducted to validate and produce normative data for the overall tuberculosis preventive practices at the bus level whoever the actor is (driver, assistant or passenger).

\section{ACKNOWLEDGMENTS}

Our earnest gratitude goes to Jimma University for its financial support used for the data collection phase of this research. We would like to thank Addis Ababa transport office, all workers of the bus stations in Addis Ababa, and data collectors for their cooperation. Similarly, our appreciation goes to study participants for their valuable cooperation and patience during data collection. We would also like to acknowledge Mr. Haftu Kahsay, who is graduate of English language and literature for editing grammatical errors of the manuscript.

\section{REFERENCES}

1. WHO: Global Tuberculosis Report 2012. Geneva 27, Switzerland. www.who.int, accessed September 2014.

2. WHO: Global tuberculosis report 2013. Geneva 27, Switzerland. www.who.int, accessed September 2014.

3. Gemeda A, Amare D, Ludwig A, Kifle W, Jaffer S, Markos $\mathrm{T}$, et al. Knowledge, Health Seeking Behavior and Perceived Stigma towards Tuberculosis among Tuberculosis Suspects in a Rural Community in Southwest Ethiopia. PLoS ONE, 2010; 5(10): e13339.

4. Mengistu L, Gobena A, Gezahegne M, Girmay M, Dawit S, Gunnar B, et al. Knowledge and perception of pulmonary tuberculosis in pastoral communities in the middle and Lower Awash Valley of Afar region, Ethiopia.BMC Public Health, 2010; 10:187.

5. Saria T, Aminur R, Anamul F M. Patient's Knowledge and Attitude towards Tuberculosis in an Urban Setting. Pulmonary Medicine, 2012;2012: 5 pages

6. Hans LR. Risk of Travel-Associated Tuberculosis. Clinical Infectious Diseases, 2001; 33:1393-1396.

7. WHO: Global tuberculosis report 2014. Geneva 27, Switzerland: 2014. WHO/HTM/TB/2014.08,www.who.int, accessed September 2014.

8. WHO: WHO policy on TB infection controls in health-care facilities, congregate settings and households. Geneva 27, Switzerland: 2009. WHO/HTM/TB/2009.419, www.who.int/tb/publicatio ns/2009/infection_control/en/, accessed October 2014.

9. Nardell, Keegan EA, Cheney J, Etkind SA. Airborne infection: Theoretical limits of protection achievable by building ventilation. Am Rev Respir Dis, 1991; 144(2):302-306.

10. Edwards LB, Dragsted I. BCG-vaccine studies. IV. Further observations on the effect of light on BCG vaccine. Bull World Health Organ, 1952; 5(3):333.

11. European Centre for Disease Prevention and Control: Investigation and control of tuberculosis incidents affecting children in congregate settings. Stockholm: 2013, ecdc.europa.eu/.../guidance-investigationcontrol-tb-incidents-children-i, accessed October 2014.

12. Centers for Disease Control and Prevention: Implementing the WHO Policy on TB Infection Control in Health-Care Facilities, Congregate Settings and Households. 2009. WHO/HTM/TB/2009.419,http://www.who.int/tb/publ ications/2009/en/index.html, accessed October 2014.

13. Galanowsky K: New Jersey Department of Health and Senior Services Practice Standard for Contact and Source Case Investigations. New Jersey, USA: globaltb.njms.rutgers.edu/.../Contact\%20Investigation \%20Manual\%20-\%, accessed October 2014.

14. Marsha L F, Larry D T, James M M, Edward A G. Giving TB wheels: Public transportation as a risk factor for tuberculosis transmission. Tuberculosis, 2011; 91: S16-S23.

15. WHO: Infection-control measures for health care of patients with acute respiratory diseases in community settings, Trainer's guide. Geneva 27, Switzerland: 2009. http://www.who.int/csr/, accessed October 2014.

16. WHO: The Stop TB Strategy Building on and enhancing DOTS to meet the TB-related Millennium Development Goals. Geneva, Switzerland: 2006. WHO/HTM/STB/2006.37,www.who.int/tb/strategy/st op_tb_strategy/en/, accessed September 2014. 
17. WHO: Tuberculosis and air travel Guidelines for prevention and control. Geneva, Switzerland: 2006. WHO/HTM/TB/2006.363,www.who.int/tb/publicatio ns/2008/WHO_HTM_TB_2008.399_eng, accessed October 2014.

18. Utah Department of Health: Office of Epidemiology: INFORMATION AND PREVENTION GUIDELINES FOR CHILD CARE CENTERS AND SCHOOLS. Utah: 2007. 1-888-EPI-UTAH (3748824),http://health.utah.gov/epi/, accessed October 2014.

19. Health Protection Surveillance Centre: Guidelines on the Prevention and Control of Tuberculosis in Ireland 2010. Dublin 1: 2010. ISBN: 978-0-9551236-58,www.hpsc.ie/A-

Z/VaccinePreventable/TuberculosisTB/Guidance/, accessed September 2014.

20. Rita L A, Howard L, Margaret D. Americans' Knowledge and Perceived Risk of Tuberculosis. Public Health Nursing 2003; 20(3): 211-215.

21. Abseno, Aseffa M, Shimelis A, Wassie E, Abebe L, Mitikie M, et al. Tuberculosis among Addis Ababa city bus drivers and cash collectors. Ethiop Med J; 2014;1:31-35.

22. Temesgen A. The Role of TRansport Sector in Ethiopia's Economic Development. Ethiopian Economic Association, 2006;9(4).

23. FDRE: Ministry of Transport: Ethiopian Roads Authority: ASSESSMENT OF 15 YEARS PERFORMANCE of ROAD SECTOR DEVELOPMENT PROGRAM. Addis Ababa, Ethiopia: 2013.

24. Ethiopian development Research Institute: Road Sector Development and Economic Growth in Ethiopia: Ethiopia Support Strategy Program II International Food Policy Research Institute, EDRI Working Paper 004. September 2011.

25. Eshetie B, Birhanu B, Daniel K. Performance Analysis on Public Bus Transport of the City of Addis Ababa. International Journal of Computer Information Systems and Industrial Management Applications, 2013; 5:722-728.

26. FDRE: Ethiopian Roads Authority: Assessment of 17 Years Performance Road Sector Development Program. Addis Ababa, Ethiopia: 2014.

27. WHO: Multidrug and extensively drug-resistant TB (M/XDR-TB): 2010 global report on surveillance and response. Geneva 27, Switzerland: WHO/HTM/TB/2010.3,http://www.who.int/iris/handl
e/10665/44286\#sthash.xkq41VoP.dpuf, accessed September 2014.

28. Liefooghe, Michiels R, Habib N, Moran S, De Muynck MB. Perception and social consequences of tuberculosis: a focus group study of tuberculosis patients in Sialkot, Pakistan. Soc Sci Med, 1995; 41(12):1685-1692.

29. West EL, Gadkowski LB, Ostbye T, Piedrahita C, Stout JE. Tuberculosis knowledge, attitude and beliefs among North Carolinian who are at increased risk of infection. N C Med J, 2008; 69(1):14-20.

30. Mushtaq MU, Shahid U, Abdullah HM, Saeed A, Omer F, Shad MA, et al.Urban-rural inequities in knowledge, attitudes and practices regarding tuberculosis in two districts of Pakistan's Punjab province. Int J Equity Health, 2011;10(1): 8.

31. FDRE: Central Statistical Agency: Population Projection of Ethiopia for All Regions at Wereda Level from 2014 - 2017. Addis Ababa, Ethiopia: 2013. http://www.csa.gov.et/, accessed October 2014.

32. Tom G: The Global Market and Developing Nations: Production and Income Classifications. [http://www.infoplease.com/cig/economics/productio n-income-classifications.html], accessed October 2014.

33. Ekwaro A O, Clea M, Jemimah K-K, Simon B, Christine A, Evelyn N, et al. Socio-demographic determinants and prevalence of Tuberculosis knowledge in three slum populations of Uganda. BMC Public Health, 2012;12(536):1471-2458.

34. Mengiste M M, Tesfay W T, Israel G T, Girmai WM M, Madeley J R. Community knowledge, attitudes and practices on pulmonary tuberculosis and their choice of treatment supervisor in Tigray, northern Ethiopia. Ethiop J Health Dev, 2005; 19(Special Issue):21-27.

35. Bati, Abdisa J, Legesse, Medhin M. Community's knowledge, attitudes and practices about tuberculosis in Itang Special District, Gambella Region, South Western Ethiopia. BMC Public Health, 1186; 13(734):1471-2458.

36. Christopher G, Pierpaolo de C, Sayohat H, Umrinisso S. Exploring TB-Related Knowledge, Attitude, Behaviour, and Practice among Migrant Workers in Tajikistan. Tuberculosis Research and Treatment, 2011; 2011:548617. 